June 2015

\title{
Priority Setting in Indigenous Health: Why We Need an Explicit Decision Making Approach
}

Michael E. Otim

Australian Catholic University, North Sydney, michael.otim@acu.edu.au

Ranmalie Jayasinha

University of Sydney, Sydney, ranmalie.jayasinha@sydney.edu.au

Margaret Kelaher

University of Melbourne, Melbourne, mkelaher@unimelb.edu.au

Edward Shane Houston

University of Sydney, Sydney, shane.houston@sydney.edu.au

Ian P. Anderson

University of Melbourne, Melbourne, ipa@unimelb.edu.au

See next page for additional authors

\section{Recommended Citation}

Otim, M. E. , Jayasinha, R. , Kelaher, M. , Houston, E. S. , Anderson, I. P. , Jan, S. (2015). Priority Setting in Indigenous Health: Why We Need an Explicit Decision Making Approach. The International Indigenous Policy Journal, 6(3).

DOI: 10.18584 /iipj.2015.6.3.8 


\title{
Priority Setting in Indigenous Health: Why We Need an Explicit Decision Making Approach
}

\begin{abstract}
Indigenous Australians have significantly poorer health outcomes than the non-Indigenous population worldwide. The Australian government has increased its investment in Indigenous health through the "Closing the Health Gap" initiative. Deciding where to invest scarce resources so as to maximize health outcomes for Indigenous peoples may require improved priority setting processes. Current government practice involves a mix of implicit and explicit processes to varying degrees at the macro and meso decision making levels. In this article, we argue that explicit priority setting should be emphasized in Indigenous health, as it can ensure that the decision making process is accountable, systematic, and transparent. Following a review of the literature, we outline four key issues that need to be considered for explicit priority setting: developing an Indigenous health "constitution," strengthening the evidence base, selecting mechanisms for priority setting, and establishing appropriate incentives and institutional structure. We then summarize our findings into a checklist that can help a decision makers ensure that explicit priority setting is undertaken in Indigenous health. By addressing these key issues, the benefits of an explicit approach, which include increased efficiency, equity, and use of evidence, can be realized, thereby maximizing Indigenous health outcomes.
\end{abstract}

\section{Keywords}

Indigenous peoples, Aboriginal people, priority setting, health, decision-making, Australia

\section{Creative Commons License}

\section{(c) 1 (i) (\$)}

This work is licensed under a Creative Commons Attribution-Noncommercial-No Derivative Works 4.0 License.

\section{Authors}

Michael E. Otim, Ranmalie Jayasinha, Margaret Kelaher, Edward Shane Houston, Ian P. Anderson, and Stephen Jan 


\section{Priority Setting in Indigenous Health: Why We Need an Explicit Decision Making Approach}

\section{Background}

Indigenous peoples everywhere - including Aboriginal and Torres Strait Islanders in Australia, referred to here as Indigenous Australians - have significantly poorer health outcomes compared to the general population in their respective countries (Australian Bureau of Statistics [ABS] \& Australian Institute of Health and Welfare [AIHW], 2010). Indigenous Australians in particular have significantly poorer health outcomes than other Indigenous populations in Canada, USA, and New Zealand (ABS \& AIHW, 2010; Gracey \& King, 2009; Kunitz \& Brady, 1995). This can be attributed to socioeconomic status and low utilisation of health care services due to limited access to good quality health care services. Even where quality health care services exist, Indigenous peoples - especially Australian ones - face structural problems, culturally inappropriate services, and institutional racism (Henry, Houston, \& Mooney, 2004). Further, dispossession and colonisation contribute to the poor health status of Indigenous Australia through loss of self-esteem and loss of resilience (ABS \& AIHW, 2010). As Archibald Meston (cited in Evans, Saunders, \& Cronin, 1993) described:

Never before had I seen aboriginal men living under extraordinary terrorism, many of them fine athletic fellows who could in case of a row have settled with their terrorisers in a very summary fashion. But many of them had long been treated as the dogs are treated and were scared into a belief that their employers wielded the power of life and death. (p. 112)

Over the years, there have been several attempts in Australia to improve the health of Indigenous peoples through reform of the health system as a means to improve Indigenous peoples' access to health services (Aboriginal \& Torres Strait Islander Commission, 1993; S. Richardson, 1997; Thomson, 1984). Most recently, the Australian government pledged in the "Close the Gap" initiative to close the gap in life expectancy and social indicators between Indigenous and nonIndigenous people within two generations (Council of Australian Government [COAG], 2009). This was followed by more reforms to the funding and delivery of health care services. However, over the years, these reforms have not been effective at achieving the government's goals (Aboriginal \& Torres Strait Islander Social Justice Commissioner, 2006). This leaves improving the priority setting process as the key issue to be addressed in order to ensure that the government's efforts at "Closing the Gap" can be done efficiently. Priority setting can be defined as a non-market based process of making choices in the face of scarcity, which arises from the demand for a good or service. Scarcity necessitates making choices, leading to the loss of other opportunities that would have been realised if investment had been done elsewhere (Culyer, 2005; Earl-Slater, 1999). There is therefore an urgent need to improve the current priority setting process in Indigenous health so that resource allocation ensures maximisation of health outcome.

In the work we recently published elsewhere (Otim, Kelaher, Anderson, \& Doran, 2014), results indicated that key decision makers from both government and Indigenous community organisations involved in Indigenous-specific health services in the Australian State of Victoria value transparent priority setting processes. Indigenous respondents revealed the need for such an approach if it allowed them to shift resources between and within programs, and was accompanied by health gains, buy-in from government, and Indigenous community involvement (Otim et al., 2014). Such an approach would encourage accountability and transparency. Thus, such results would be useful as criteria for explicit priority setting (Maynard, 1996; Mooney, Gerard, Donaldson, \& Farrar, 1992). 
Explicit priority setting is when the choices made by decision makers are publicly known and bases for such decisions are publicly known too (Earl-Slater, 1999). However, how to implement explicit priority setting in Indigenous settings has not been undertaken.

The primary aim of this article is therefore to provide a framework for improving priority setting and describe how such a framework can be implemented in practice. We explore the role of criteria or principles that guide the health system and associated weights, engagement of the Indigenous community, and the role of shifting resources within and across programs to maximise outcomes. As one government respondent indicated, it is the burden of disease and its distribution that guides his decision making process. When asked if that is enough for maximising population health (Otim, et al., 2014), he said, "for me the most important issues would be equity... and the size of the health burden would be an issue but not the overriding factor" (Otim, et al. 2014, Perceptions of the current process of setting priorities section, para. 3 ).

\section{Improving Priority Setting: The Role of Explicit Priority Setting in Indigenous Health}

Undertaking explicit priority setting to improve decision making in Indigenous health requires addressing four key issues, identified from the literature (Carter, et al., 2008; Earl-Slater, 1999; Mooney \& Wiseman, 1999; Shiell \& Mooney, 2002):

a. The establishment of an Indigenous health constitution;

b. Strengthening of the Indigenous evidence base for decision making;

c. The adoption of a decision making mechanism to resource allocation;

d. The establishment of an appropriate incentive and institutional structure.

\section{Developing an Indigenous Health Constitution}

The development of an Indigenous health constitution involves establishing the broad principles or criteria that should guide the health system and the trade-offs that Indigenous people are prepared to make (Shiell \& Mooney, 2002). These principles or criteria can be used for determining the extent to which programs or interventions should be publicly provided or financed and the relative importance of each criterion and therefore their relative weights. As one Indigenous community member expressed her frustration with the way funding agencies allocated resources: "I would be happy to know what reasons the funders use to select programs or services to fund. Most importantly, I would like to know the reasons why they have not funded some of our activities" (Otim et al., 2014, Assessment of the current priority setting process section, para. 2).

Different countries use different criteria to guide priority setting (Kapiriri \& Norheim, 2004). Some of them publish their criteria and others do not (Table 1). The publication of Nordic countries' criteria served to address political issues in funding and access to health care services, thus ensuring transparency and accountability by these governments. These criteria also provided guidance to the development of the guidelines for assessing the successes of the different priority setting frameworks that had been employed (Sabik \& Lie, 2008). The literature suggests that successful processes have involved the presence of priority setting commissions (Sabik \& Lie, 2008). 
Table 1. Examples of Criteria for Priority Setting from Selected Countries

\begin{tabular}{|c|c|c|}
\hline $\begin{array}{l}\text { Country or } \\
\text { Region }\end{array}$ & Criteria & Source \\
\hline Oregon & Cost-effectiveness; then equity & (Oberlander \& Marmor, 2001) \\
\hline $\begin{array}{l}\text { Netherlands } \\
\text { (filter mode) }\end{array}$ & $\begin{array}{l}\text { Service necessity; effectiveness; efficiency; } \\
\text { and personal responsibility }\end{array}$ & $\begin{array}{l}\text { (Government Committee on } \\
\text { Choices in Health Care, 1992) }\end{array}$ \\
\hline Sweden & $\begin{array}{l}\text { Human dignity; equal rights; need; } \\
\text { solidarity; and cost-efficiency }\end{array}$ & $\begin{array}{l}\text { (Health Care and Medical Priorities } \\
\text { Commission, 1993) }\end{array}$ \\
\hline Denmark & Equality, solidarity, security, and autonomy & (Danish Council of Ethics, 1997) \\
\hline $\begin{array}{l}\text { New Zealand } \\
\text { (Maori) }\end{array}$ & $\begin{array}{l}\text { Efficiency; effectiveness; equity; } \\
\text { acceptability; and Maori health principles }\end{array}$ & $\begin{array}{l}\text { (Ashton, Cumming, \& Devlin, 2000; } \\
\text { Tito \& Kavanagh, 2004) }\end{array}$ \\
\hline Uganda & $\begin{array}{l}\text { Efficiency/accountability; effectiveness/ } \\
\text { quality care; } \\
\text { equity/fairness/justice/ethics; and } \\
\text { national solidarity/cultural practices }\end{array}$ & (Kapiriri \& Norheim, 2004) \\
\hline Canada & $\begin{array}{l}\text { Maximisation; egalitarianism; claims such } \\
\text { as severity, human rights, etc. }\end{array}$ & (Shiell \& Mooney, 2002) \\
\hline West Australia & Need; socioeconomic disadvantage; access & (Mitton \& Prout, 2004) \\
\hline $\begin{array}{l}\text { Torres Strait, } \\
\text { Queensland }\end{array}$ & $\begin{array}{l}\text { Public outrage; burden of disease; cost; } \\
\text { preventability; national priorities }\end{array}$ & (McDermott \& Mills, 2004) \\
\hline
\end{tabular}

Indeed, lessons from previous studies such as those identified above suggest that a set of criteria ought to be culturally or system specific (Otim et al., 2014; Shiell \& Mooney, 2002). Whilst useful in conceptualising possible criteria, these may be divergent from the experiences of Indigenous peoples.

In recognition of Indigenous values, there have been a few attempts in Australia at identifying principles that should guide priority setting and/or resource allocation in Indigenous health and research (Monk, Rowley, \& Anderson, 2009; National Aboriginal and Torres Strait Islander Health Council [NATSIHC], 2003; National Health and Medical Research Council [NHMRC], 1993, 2003; Otim et al., 2014). Results indicate that the key principles include cultural respect, community control, and capacity building within the Indigenous community controlled health sector, provider collaboration, localised decision making, accountability, justice, quality of life, and social worth. Such criteria highlight the importance that Indigenous peoples and decision makers attach to the role of evidence, such as economic evaluation. Having an Indigenous health constitution would inform the debate on the appropriateness of the criteria and their relative weights for decision making in Indigenous health. 


\section{Strengthening the Evidence Base}

The second step in the development of explicit priority setting is the strengthening of the evidence base in Indigenous health that can be used to guide the process of setting priorities. This is part of the "evidence based policy making" discussion, which has been around for a long time and may be linked to evidence-based clinical decision making. However, several key issues have been identified to explain why policy makers fail to use evidence and why researchers fail to produce useful evidence (Banks, 2009; Otim, et al., 2014; Ross, 1995). These issues include the complex processes involved in policy processes; lack of relevant and timely evidence, such as economic evaluation and epidemiological evidence for decision making; necessary improvement in the quality and the measurement rigour of such evidence; and the need for a holistic approach to Indigenous health policy.

Furthermore, the criteria for assessing the quality of evidence might need to be widened and strengthened. Widening the evidence base to guide decision making ought to include a combination of technical rigour and value judgments about what constitutes benefits or costs (Mooney, 2006). Technical judgements may rely on the availability and quality of data and technical methods for making decisions.

Value judgements rely on the principles and values of the decision makers and the Indigenous population. When data are not readily available, value judgements may be used in the process of assessing the quality of evidence in Indigenous health, which would ensure that interventions targeting Indigenous health are not penalised for lack of high quality evidence (Rychetnyk, Frommer, Hawe, \& Shiell, 2002; Sibthorpe et al., 2002).

\section{Selecting Mechanisms for Priority Setting}

The third issue involves the need for practical decision making mechanisms to ensure that resource allocation decisions are consistent with the principles embodied in the Indigenous health constitution and trade-offs can be undertaken. In practice, decision making happens at the margin; small incremental adjustments to an existing plan of action, in accordance with the concept of marginal analysis (Mooney, 2002). Knowing that marginal analysis is a tool for estimating efficiency of government actions, it is important that a clear specification of the objectives being pursued is made so that an appropriate framework that can address such objectives can be selected. An ideal priority setting framework should be able to shift resources matched with health gain, and be able to have an impact on the health of Indigenous peoples (Otim et al., 2014). Further, such an approach ought to be able to use both technical evidence and due process, which may require resources and structures for collating such evidence and expertise. First, the decision makers have to buy-in to the idea of implementing a priority setting model that has potential to maximise health outcomes.

\section{Putting Appropriate Incentives and Institutional Structure in Place}

Buy-in by funding agencies is important since Indigenous providers are already overbudened by limited funding, as well as administrative and multiple accounting requirements from the funding agencies (Dwyer, O'Donnell, Lavoie, Marlina, \& Sullivan, 2009). This would ensure that the priorities identified are acted upon and staff are trained in the chosen priority setting framework to ensure its adoption as a routine decision making tool (Shiell \& Mooney, 2002). Thus, funding agencies would need to put in place incentives and institutional structures for Indigenous providers. 
Incentives can be put in place by funding agencies to encourage Indigenous community providers to use the chosen approaches for routine decision making. Other requirements would involve ensuring Indigenous ownership of the process and the results, organisational stability of Aboriginal Community Controlled Health Services (ACCHS), and organisational decision making culture to focus on the costs and benefits. It is therefore imperative for the funding agencies to financially support the implementation of a new way of priority setting in ACCHS. Thus, for Indigenous health providers to be able to adopt explicit priority setting, appropriate incentives, and institutional structures would need to be established. The key challenge is how all the above issues can be translated into practice to ensure the implementation of the explicit priority setting in Indigenous health. Thus, there is a need to invest in the establishment of the institutional structures that are needed to support a systematic approach to priority setting (Ham \& Coulter, 2000).

\section{Implementing Explicit Priority Setting: Practical Issues in Indigenous Health}

In the following section, we consider some of the challenges that ought to be addressed in order to allow explicit priority setting processes to be implemented in Indigenous health. A checklist is later developed to guide such a process and it is summarised in Table 2.

\section{Identifying the Goal that is Being Pursued}

The first task is to specify what goal is being pursued explicitly, and within a specific context. This will enable priority setting to occur within a pre-defined framework. Under economic theory, for example, maximising health should be one of the key objectives, and, under non-economic theories, other objectives exist such as equity, equality, fairness, and need (Otim et al., 2014). Thus, optimising or maximising health, and improving access and equity, while ensuring Indigenous engagement in the process, could be the key goals.

The challenge, however, is how to make the objectives as discrete as possible due to the potential for overlap in certain areas, especially in cases where more than one objective may be stated. For example, "equality of health" overlaps with "equality of outcomes" or "equality of use," but differs significantly. The similarities and differences ought to be reflected and captured in the priority setting approach used for the maximisation of health. Thus, the objectives have to be as clearly stated as possible and framed in an answerable manner.

\section{Engaging the Indigenous Community}

The second task is how to engage the Indigenous community in the decision making process in a meaningful manner. That is, the Indigenous community should be involved in the formulation of the objectives, identification of the priorities, and their implementation. To identify priorities and criteria to be used in priority setting, the key findings of the Harvard Project, for example, indicate that sovereignty matters in the Native American lands development (Jorgensen \& Taylor 2000). Further, good governance, cultural issues, and institutions are important pillars for development and sustainability (Cornell 2002; Dodson \& Smith 2003). Therefore, an approach that ensures the above issues are incorporated in the decision making process can ensure that the Indigenous community is likely to accept and/or embrace the choices made by decision makers, and will ensure ownership and sustainability of the selected services or strategies. Several authors argue that Indigenous Australian communities are in crisis and this is widely acknowledged in the literature (Dodson 2003; Sutton 2001). This crisis is mainly one of governance. From whichever perspective this crisis is viewed, be it anthropological or economic analysis, what matters most is that the health 
outcomes of Indigenous peoples must improve to a level that is comparable to the rest of the nonIndigenous population. Such an improvement can only be achieved with good governance and institutions that are influenced by cultural issues. In Australia, several comprehensive primary health care services are Aboriginal community controlled. This allows control and engagement of the community in the decision making process.

Thus, the governance process that allows and incorporates Indigenous cultural and other values in the setting of priorities, and aids Indigenous institutions to choose and implement those strategies is likely to maximise health gain. From an economic perspective, Indigenous values can be incorporated into the health system through empirical ethics (J. Richardson, 2000) or a communitarian approach, which emphasises the need to use the preferences of that marginalised group to address their disadvantage (Mooney, 1998). This approach classifies reasons for a person's claim for a good into two groups: "communitarian claims" and "other reasons" (Mooney, 1998). To understand individuals in society, especially when undertaking priority setting, one must look at the community from where the individual comes and their communal relationships (Avineri \& deShalit, 1992). Thus, this requires the promotion of community control and self-determination in priority setting. For example, Indigenous Australian management structures could provide a mechanism for the engagement of the Indigenous community in the decision making process. In a study of decision makers from both government and Indigenous communities that we undertook, respondents identified cultural security, individual health gain, community gain, and access as important key outcomes of any allocation of resources especially in health (Otim et al., 2014). Knowing that Indigenous peoples everywhere are not a homogenous group, it is important to undertake empirical studies to elicit the broad principles from Indigenous peoples and communities that should guide the priority setting process and what weights should be attached to those criteria.

\section{Empirical Elicitation of Criteria to Establish Indigenous Health Constitution}

The next task involves how to elicit the broad criteria that should guide the priority setting process and the associated weights to be attached to these criteria. In essence, these criteria should include the Indigenous values and aspirations (Mooney, 2000, 2002, 2003, 2010; Mooney \& Houston, 2004; Mooney \& Wiseman, 1999; Shiell \& Mooney, 2002). Eliciting such criteria can be done using empirical ethics (J. Richardson, 2000) or communitarian claims approach (Mooney, 2002, 2010). These approaches can also elicit preferences for weighting the criteria for their relative importance. Publishing such criteria and the associated weights can allow the public to have a debate on the appropriateness and acceptability of each.

J. Richardson (2000) argued that social ethics ought to guide the decision-maker's health policy objectives, and these ethical issues should be captured using the "empirical ethics" approach. This would involve ethical values being subjectively derived from a sample of Indigenous individuals within the population and these values being subjected to ethical analysis and criticism. These values can then be quantified and converted into a scale that can be used to weight the importance of decision criteria or health outcomes (J. Richardson, 2000). In the event that the social values are shown to lead to abhorrent outcomes, such as racism, sexism, or discrimination, then preferences should be "laundered," and an iterative process undertaken between the ethicist and the public. However, this approach has not yet been applied in Indigenous health.

The communitarianism claims approach advocates for the use of community preferences as the basis for criteria, and argues that these same members are the most appropriate to determine what weights to attach to these preferences (Mooney \& Russell, 2003). These criteria would be elicited using 
citizenry workshops (Mooney, 2010) and used to inform the selection of the options for change, the weighting of the scores, and interpretation of the findings. Thus, the use of ethical values or principles that are carefully inferred from the respondents, and together with evidence, is likely to lead to desirable outcomes from the priority setting process.

\section{Investment in Strengthening Evidence}

Developing a strong evidence base is another key aspect of explicit decision making, which promotes the systematic collection of data relating to the costs and benefits of interventions or programs. This evidence may be in the form of epidemiology data, economic evaluation evidence, or political incentives. Evidence gathered from economic evaluation, for example, ensures that maximising outcomes for a given budget can be achieved (Feldman \& Serrano, 2006; Tsuchiya \& Williams, 2001).

In practice, the number of economic evaluation studies has been increasing worldwide since the 1970s (Gerard \& Mooney, 1993). In Australia, an increasing number of economic evaluations studies have been adopted for policy purposes. For example, the Australian government uses economic evaluation to make choices on what pharmaceutical products or medical devices and procedures it subsidises. This evidence has also been used in other areas such as, breast and cervical cancer screening, organ transplantation, co-ordinated care trials, the Cancer Council National Strategy, and the National Tobacco Control strategy. However, very few such studies have been done specifically in Indigenous health and hence the uptake of economic evaluation evidence in priority setting is not known.

Alternatively, epidemiologically based studies may include the burden of disease studies, community surveys, and setting goals and targets to be achieved either at an individual or a societal level. However, these data can fail to capture equity and other social justice issues in Indigenous health, unless guided by objectives that explicitly promote these principles. Whilst each source of data has its own challenges, explicitly accounting for these issues and choosing an appropriate method is important to ensuring the results are relevant to the intervention to be implemented.

\section{Decision Making Mechanisms}

There are several frameworks for priority setting from both non-economic and economic disciplines. Examples of economic-based approaches include the league table approach, the Health Sector-Wide (HSW) model (Segal \& Mortimer, 2006), Health Benefit Groups/Health Resources Groups (HBG/HRG) (Beaver, Williams, Zhao, \& Weeramanthari, 1999; McDermott, 2004; McDermott \& Mills, 2004), and Program Budgeting and Marginal Analysis (PBMA) (Gruskin \& Daniels, 2008).

Whereas, non-economic frameworks include historically based allocations, needs assessments (burden of disease, cost of illness, community surveys, goals and targets), and clinical guidelines and protocols (defining core services, best practice guidelines, and shared protocols) (Carter, et al., 2008; Mitton \& Donaldson, 2004; Segal \& Mortimer, 2006). Non-economic based approaches emphasise the explicitness of the values and criteria that ought to guide priority setting, and the active involvement of the Indigenous stakeholders in the process. For example, ethically based approaches such as the accountability for reasonableness approach and a human rights-based approach have potential to improve priority setting (Daniels, 2000; Gruskin \& Daniels, 2008; Kapiriri, Norheim, \& Martin, 2007; Martin, Giacomini, \& Singer, 2002; Mitton \& Donaldson, 
2004). However, these approaches do not have decision making mechanisms that can be used to maximise health gain.

\section{Establishment of Incentives and Institutional Support}

It is vital that the funding bodies create environments that promote the ACCHS use of priority setting methods if the funders hope to see service providers use formal methods to set priorities (Peacock, 1998; Shiell \& Mooney, 2002). This would legitimise the decisions made and increase the potential acceptance and adoption of the results. Additionally, buy-in by funders is needed to fund project support.

The Australian government is increasingly concerned with ensuring the risk management by ACCHS. Dwyer and colleagues (2009) have proposed that long-term contracting for core primary health care services should be the basis for the funder-provider relationship. This would allow flexibility for local priority setting, in accordance with agreed plans, and subsequently reduce transaction costs. The funders would therefore need to establish appropriate incentives and structures within their funding guidelines to ensure that the priorities identified by the organisations are acted upon, the chosen priority setting framework is adopted as routine decision making tool, and such a tool is not a burden to community-based organisations. Furthermore, integrating the values of the community and decision makers into the program design and delivery may further support their buy-in to the priority setting process.

\section{Practical Checklist for Explicit Priority Setting}

The ideal explicit priority setting framework should be able to shift resources matched with health gain, and should be able to engage Indigenous peoples in the process to ensure self-determination. In Table 2, we have summarised the key issues for consideration when undertaking explicit priority setting in Indigenous health and presented them as brief checklist. The checklist provided is not intended to be exhaustive; rather, it should be viewed as a starting point for considering how an explicit priority setting can be adopted. We recommend that the checklist be modified based on the context of the organisation, so that explicit priority setting can be harnessed appropriately and effectively to meet the goals and objectives of government and Indigenous organisations.

\section{Conclusion}

Explicit priority setting is not necessarily and universally more valid and reliable than implicit judgement. However, we argue that it makes use of both technical information and due process, and has the potential to engage Indigenous people for three reasons. First, decisions and the criteria behind decisions will be transparent. Second, evidence, such as economic evaluation, is important in assisting decision makers with the selection of interventions that work and also offer value for money. Third, in line with the Indigenous principle of self-determination, due process enables engagement of Indigenous people in the decision making process. This helps to ensure that Indigenous values are incorporated in the choices, and that Indigenous ownership of the process and the results is achieved. As such, the openness and accountability of the decision making process can be ensured. 
Table 2. Checklist for Priority Setting in Indigenous Health

Step 1 Identifying a well-specified and answerable goal

- Are the objectives of the exercise clearly specified?

- Are comparators specified?

- Is the perspective for decision making specified?

Step 2 Establishing the Indigenous health constitution

- Are criteria for making decisions clearly stated and ranked for relative important?

- Does the framework recognise access issues to culturally appropriate and effective heath care?

- Are Indigenous values embodied in the framework as guiding principles?

- Does the framework address issues of fairness or equity?

Step 3 Choosing a decision making framework

- Is the framework appropriate to the question and context that is specified?

- Does the framework allow for a fair and open process to priority setting?

- Is efficiency and equity an integral rule for making judgment?

Step $4 \quad$ Strengthening the evidence base

- Is expert advice used where data may not be available or of poor quality?

- Is marginal analysis an integral component of the framework?

- Are the data needs manageable or tractable?

Step 5 Promoting community involvement

- Is the right of Indigenous people to control their health care being respected?

- Are the Indigenous community's decision making, participation and control supported?

- Are there effective structures and processes to ensure effective Indigenous participation?

Step 6 Ensuring incentives and institutional support

- Does the framework contribute to capacity building in Indigenous health services?

- Is the role of judgment recognised in the specification and interpretation of the results?

- Is there capacity for the implementation of the results? 
We argued that a key challenge is how to translate an explicit approach to priority setting into practice in Indigenous health. From normative economic and social justice perspectives, this can be done by using a clearly specified criteria; frameworks that allow maximisation of health outcomes; use of evidence, incentives, and institutional support; and effectively involving Indigenous peoples in the process. Accounting for these considerations will ensure that the choices made reflect Indigenous values and aspirations, and offer value for money; thereby, maximising the health of Indigenous Australians. 


\section{References}

Aboriginal \& Torres Strait Islander Commission. (1993). Annual report 1992-93. Canberra: Aboriginal and Torres Strait Islander Commission.

Aboriginal \& Torres Strait Islander Social Justice Commissioner. (2006). Social justice report 2006. Sydney: Human Rights and Equal Opportunity Commission.

Ashton, T., Cumming, J., \& Devlin, N. (2000). Priority setting in New Zealand: Translating principles into practice. Journal of Health Services \& Research Policy, 5(3), 170-175.

Australian Bureau of Statistics (ABS), \& Australian Institute of Health and Welfare (AIHW). (2010). The health and welfare of Australia's Aboriginal and Torres Strait Islander peoples-2010 (Cat. no. 4704. 0). Canberra: Australian Bureau of Statistics and Australian Institute of Health and Welfare.

Avineri, S., \& de-Shalit, A. (1992). Introduction. In S. Avineri \& A. de-Shalit (Eds.), Communitarianism and individualism. Oxford: Oxford University Press.

Banks, G. (2009). Evidence-based policy making: What is it? How do we get it? Canberra: Australian Government.

Beaver, C., Williams, K., Zhao, Y., \& Weeramanthari, T. (1999). A model for addressing allocative efficiency across the disease continuum. Darwin: Territory Health Services.

Carter, R., Vos, T., Moodie, M., Haby, M., Magnus, A., \& Mihalopoulis, C. (2008). Priority setting in health: Origins, description and application of the Australian Assessing Cost-Effectiveness initiative. Expert Review in Pharmacoeconomics Outcomes Research, 8, 593 - 617.

Cornell, S. (2002). What is institutional capacity and how can it help American Indian nations meet the welfare challenge. Paper prepared for the symposium on Capacity Building and Sustainability of Tribal Governments, St Louis, Washington University.

Coucil of Australian Government (COAG). (2009). Closing the gap on Indigenous disadvantage: The challenge for Australia. Canberra: Commonwealth of Australia.

Culyer, A. (2005). The dictionary of health economics. Cheltenham: Edward Elgar.

Daniels, N. (2000). Accountability for reasonableness in private and public health insurance. In A. Coulter \& C. Ham (Eds.), The global challenge of health care rationing (pp. 89 - 106). Buckingham: Open University Press.

Danish Council of Ethics. (1997). Priority setting in the Health Service. Retrieved from http://etiskraad.dk/upload/publications-en/misc/priority-setting-in-health.htm

Dodson, M. (2003). The end in the beginning: Re(de)finding Aboriginality. In M. Grossman (Ed.), Blacklines: Contemporary critical writing by Indigenous Australians (pp. 25-42). Melbourne: Melbourne University Press. 
Dodson, M., \& Smith, D. (2003). Governance for sustainable development: Strategic issues and principles for Indigenous Australian communities (Centre for Aboriginal and Economic Policy Research Discussion Paper 250). Canberra: Australian National University.

Dwyer, J., O'Donnell, K., Lavoie, J., Marlina, U., \& Sullivan, P. (2009). The overburden report: Contracting for Indigenous health services: Summary report [online]. Aboriginal and Islander Health Worker Journal, 33(6), 24-26.

Earl-Slater, A. (1999). Dictionary of health economics. Abingdon, Oxon: Radcliffe Medical Press.

Evans, R., Saunders, K., \& Cronin, K. (1993). Race relations in colonial Queensland: A history of exclusion, exploitation, and extermination (3rd ed.). Brisbane: University of Queensland Press.

Feldman, A., \& Serrano, R. (2006). Welfare economics and social choice theory (2nd ed.). New York: Springer.

Gerard, K., \& Mooney, G. (1993). QALY league tables: Handle with care. Health Economics, 2(1), 59-64.

Government Committee on Choices in Health Care. (1992). Choices in health care. Rijwsijk, The Netherlands: Ministry of Welfare, Health and Cultural Affairs.

Gracey, M., \& King, M. (2009). Indigenous health part 1: Determinants and disease patterns. The Lancet, 374, 65-75.

Gruskin, S., \& Daniels, N. (2008). Process is the point: Justice and human rights: Priority setting and fair deliberative process. American Journal of Public Health, 98(9), 1573-1577.

Ham, C., \& Coulter, A. (2000). Introduction: International experience of rationing (or priority setting). In A. Coulter \& C. Ham (Eds.), The global challenge of health care rationing. Buckingham, Philadelphia: Open University Press.

Health Care and Medical Priorities Commission. (1993). No easy choices: The difficult priorities of healthcare. Stockholm: Ministry of Health and Social Affairs.

Henry, B., Houston, S., \& Mooney, G. (2004). Institutional racism in Australian healthcare: A plea for decency. Medical Journal of Australia, 180(10), 517-520.

Jorgenson, M., \& Taylor, J. (2000). What determines Indian economic success? Evidence from tribal and individual Indian enterprises. Cambridge: Harvard Project on American Indian Economic Development, Harvard University.

Kapiriri, L., \& Norheim, O. (2004). Criteria for priority setting in health care in Uganda: Exploration of stakeholders' values. Bulletin of the World Health Organization [NLM - MEDLINE], $82(3), 172$.

Kapiriri, L., Norheim, O. F., \& Martin, D. K. (2007). Priority setting at the micro-, meso- and macro-levels in Canada, Norway and Uganda. Health Policy, 82(1), 78-94. 
Kunitz, S. J., \& Brady, M. (1995). Health care policy for Aboriginal Australians: The relevance of the American Indian experience. Australian Journal of Public Health, 19(6), 549-58.

Martin, D. K., Giacomini, M., \& Singer, P. A. (2002). Fairness, accountability for reasonableness, and the views of priority setting decision-makers. Health Policy, 61(3), 279-290.

Maynard, A. (1996). Rationing health care. British Medical Journal, 313, 1499.

McDermott, R. (2004). Why money alone is not the answer: The need to improve effectiveness in Indigenous primary health care. In M. Otim, I. Anderson, \& I. Scott (Eds.), Economics and Indigenous Australian health policy. Melbourne: VicHealth Koori Health \& Community Development Unit.

McDermott, R., \& Mills, P. (2004). Public health priority setting: Case study from the Torres Strait. In M. Otim, I. Anderson, \& I. Scott (Eds.), Economics and Indigenous Australian health policy. Melbourne: VicHealth Koori Health \& Community Development Unit, The University of Melbourne.

Mitton, C., \& Donaldson, C. (2004). Priority setting toolkit: A guide to the use of economics in healthcare decision making. London: BMJ Publishing Group.

Mitton, C., \& Prout, S. (2004). Setting priorities in the south west of Western Australia: Where are we now? Australian Health Review, 28(3), 301.

Monk, J., Rowley, K., \& Anderson, I. P. (2009). Setting and meeting priorities in Indigenous health research in Australia and its application in the Cooperative Research Centre for Aboriginal Health. Health Reservices and Policy Systems, 7, 25.

Mooney, G. (1996). And now for vertical equity? Some concerns arising from Aboriginal health in Australia. Health Economics, 5, 99-103.

Mooney, G. (1998). Economics, communitarianism, and health care. In M. Bearer, T. Getzen \& G. Stoddart (Eds.), Health, health care and health economics. Chichester: John Wiley and Sons.

Mooney, G. (2000). Judging goodness must come before judging quality-But what is the good of health care? International Journal for Quality in Health Care, 12(5), 389-94.

Mooney, G. (2002). Priority setting in mental health services. Applied Health Economics \& Health Policy, 1(2), 65-74.

Mooney, G. (2003). Inequity in Australian health care: How do we progress from here? Australian \& New Zealand Journal of Public Health, 27(3), 267-270.

Mooney, G. (2006). Priority setting: The biggest gap in Australian health planning? Sydney: Centre for Policy Development.

Mooney, G. (2010). A handbook on citizens' juries with particular reference to health care.

Retrieved from 
http://www.newdemocracy.com.au/docs/researchpapers/Mooney_CJ_BookJanuary2010. pdf

Mooney, G., Gerard, K., Donaldson, C., \& Farrar, S. (1992). Priority setting in purchasing: Some practical guidelines. Aberdeen: Health Economics Research Unit, University of Aberdeen.

Mooney, G., \& Houston, S. (2004). An alternative approach to resource allocation: Weighted capcity to benefit plus MESH infrastructure. Applied Health Economics \& Health Policy, 3(1), 29-33.

Mooney, G., \& Russell, E. (2003). Equity in health care: The need for a new economics paradigm? In A. Scott, A. Maynard \& R. Elliot (Eds.), Advances in health economics. Chichester: John Wiley.

Mooney, G., \& Wiseman, V. (1999). A 'constitution' for health services. Journal of Health Services \& Research Policy, 4(4), 195-6.

National Aboriginal and Torres Strait Islander Health Council (NATSIHC). (2003). National strategic framework for Aboriginal and Torres Strait Islander health: Framework for action by governments (pp. 1-40). Canberra: National Aboriginal and Torres Strait Islander Health Council.

National Health and Medical Research Council (NHMRC). (1993). Ethical considerations relating to health care resource allocation decisions. Canberra: Commonwealth of Australia.

National Health and Medical Research Council (NHMRC). (2003). Values and ethics: Guidelines for ethical conduct in Aboriginal and Torres Strait Islander health research. Canberra: Commonwealth of Australia.

Oberlander, J., \& Marmor, L. (2001). Rationing and medical care: Rhetoric and reality in the Oregon Health Plan. Canadian Medical Association Journal, 164, 1583-1587.

Otim, M. E. , Kelaher, M., Anderson, I. P., \& Doran, C. M. (2014). Priority setting in Indigenous health: Assessing priority setting process and criteria that should guide the health system to improve Indigenous Australian health. International Journal for Equity in Health, 13(45). doi: 10.1186/1475-9276-1113-1145.

Peacock, S. (1998). An evaluation of program budgeting and marginal analysis applied in South Australian Hospitals (pp. 1-37). Melbourne: Centre for Health Program Evaluation, Monash University.

Richardson, J. (2000). Empirical ethics verses analytical orthodoxy: Two contrasting bases for the reallocation of resources. In A. H. E. Society (Ed.), Twenty-second Australian Conference of Health Economists, Gold Coast.

Richardson, S. (1997). The politics of Aboriginal health in Australia since the Working Party. Challenging Public Health, 1, 58-69.

Ross, J. (1995). The use of economic evaluation in health care: Australain decision-maker' perceptions. Health Policy, 31, 103-110. 
Rychetnyk, L., Frommer, M., Hawe, P., \& Shiell, A. (2002). Criteria for evaluating evidence of public health interventions. Journal of Epidemiology and Community Health, 56, 119-127.

Sabik, L., \& Lie, R. (2008). Priority setting in health care: Lessons from the experiences of eight countries. International Journal for Equity in Health, 7(1), 4.

Segal, L., \& Mortimer, D. (2006). A population-based model for priority setting across the care continuum and across modalities. Cost Effectiveness and Resource Allocation, 4(6). doi:10.1186/1478-7547-4-6

Shiell, A., \& Mooney, G. (2002). A framework for determining the extent of public financing of programs and services. Commission on the future of health care in Canada (Discussion paper No.6).

Sibthorpe, B. M., Bailie, R. S., Brady, M. A., Ball, S. A., Sumner-Dodd, P., \& Hall, W. D. (2002). The demise of a planned randomised controlled trial in an urban Aboriginal medical service. Medical Journal of Australia, 176(6), 273-276.

Sutton, P. (2001). The politics of suffering: Indigenous policy in Australia since the seventies. Anthropological Forum, 11(2),125-173.

Thomson, N. (1984). Australian Aboriginal health and health-care. Social Science and Medicine, 18(11), 939-948.

Tito, K., \& Kavanagh, J. (2004). Achieving health gain for Mäori through an institutional prioritisation process - The realisation of whänau ora. Paper presented at the 5th International Conference on Priorities in Health Care, Wellington.

Tsuchiya, A., \& Williams, A. (2001). Welfare economics and economic evaluation. In M. Drummond \& A. McGuire (Eds.), Economic evaluation in health care: Merging theory with practice. Melbourne: Oxford University Press. 